American Journal of Environmental Sciences 8 (1): 25-34, 2012

ISSN 1553-345X

(C) 2012 Science Publications

\title{
Detention Pond Sediment Accumulation Prediction using Monte Carlo Simulation
}

\author{
${ }^{1}$ Supiah Shamsudin, ${ }^{1}$ Abd Rashid Mohd Darom, \\ ${ }^{2}$ Irma Norazurah Mohamad and ${ }^{3}$ Azmi Ab Rahman \\ ${ }^{1}$ Razak School of Engineering and Advanced Technology, \\ ${ }^{2}$ Department of Civil Engr, Faculty of Civil Engineering, \\ University Technology Malaysia (UTM), 81310 Skudai, Johor, Malaysia \\ ${ }^{3}$ Perdana School of Science Technology and Innovation (STI) Policy, \\ University Technology Malaysia, International Campus, 54100, Kuala Lumpur, Malaysia
}

\begin{abstract}
Problem statement: A study in Malaysia had been carried out to predict the sediment accumulation in urban detention ponds. Suspended sediment is pollutant of primary concern to the river that results in adverse environmental effect. Detention pond becomes a practical approach to this problem. Suspended sediment that settled in stormwater detention pond, can bring effect to the detention pond functions. Questions were raised on how certain were the observed and predicted values of sediment depth and load accumulation estimations. Secondly the question was what the sediment accumulation be in the next 100 years. The uncertainties of sediments estimation vary greatly due to the hydrological variability and rainfall random nature obtain the relationship between flow discharge and suspended sediment rate using on-site data collection at UTM and Ledang Heights, Nusajaya. Predict accumulated sediment loads and depth from MUSLE over 10-100 years. Analyze the uncertainties of sediment loads and depth using Monte Carlo Simulation (MCS) combining normal distribution. Obtain the maximum probability of occurrence of sediment loads and depth in the detention pond. Approach: Modified Universal Soil Loss Equation (MUSLE) and Trap Efficiency (TE) Method was applied to predict sediment accumulation. This uncertainty of sediment loads and depth was carried out using Monte Carlo Simulation (MCS) Method. The water samples were collected for suspended solids data and other water quality parameters at Ledang Heights, Nusajaya, Johor and University Technology Malaysia (UTM), Johor. Sampling station were randomly selected at the inlet and outlet of the detention pond. The hydrological parameters such as flow and velocity were also collected. Results: The simulation results showed the maximum probability of occurrence value for observed sediment loads and sediment depth from Ledang Heights were 0.0062 tons $(16.5 \%)$ and $0.0005 \mathrm{~mm}(17.5 \%)$ respectively. The maximum probability of occurrence values for observed sediment loads and sediment depth at UTM showed no obvious differences with Ledang Heights; about 0.015 tons $(16.8 \%)$ and $0.00037 \mathrm{~mm}(15.5 \%)$ respectively. The maximum occurrence of predicted sediment loads and sediment depth using MUSLE method for Ledang Height was 77.8 tons $(16.8 \%)$ and $7.5 \mathrm{~mm}(26.8 \%)$ respectively. The maximum occurrence for UTM was slightly higher, about 264 tons (15.70\%) and $7.0 \mathrm{~mm}(21.10 \%)$ respectively. The higher values for UTM were suspected due to its larger watershed. The sediment loads and depths were also predicted for the next 50-100 years considering no significant watershed land use changes. Conclusion: The sediment accumulation estimation and forecasting are very important to ensure the effectiveness and proper operation of the detention pond. The continuous effort through natural sediment control measures such as proper vegetation and grass inplants are always encourage around the detention pond and surrounding areas throughout its lifespan.
\end{abstract}

Key words: Sediemnt loads, accumulation, Total Suspended Solid (TSS), detention pond, Universal Soil Loss Equation (USLE), monte carlo

Corresponding Author: Supiah Shamsudin, Razak School of Engineering and Advanced Technology, University Teknologi Malaysia, International Campus, 54100, Kuala Lumpur, Malaysia 
Am. J. Environ. Sci., 8 (1): 25-34, 2012

\section{INTRODUCTION}

Detention ponds are one of the most popular methods to solve water pollution such as suspended and bedded sediment problem. Basically, detention ponds may provide three basic functions that are flood control, water quality enhancement and ecological and aesthetic value USA-EPA 2009. Excessive suspended sediment settled in the detention pond, may affect the detention pond functions. Therefore to ensure the detention ponds work effectively, the sediment, suspended solid and any materials was settled in the ponds should be removed. This will maximize the efficiency of the pond operation and reduce the risk of water pollution downstream.

Two case studies were investigated; at Ledang Height, Nusajaya and Universiti Teknologi Malaysia (UTM), both located at Southern Malaysia, Johor. This study is related to sediment loads and depth accumulation estimation and prediction.This study provides the estimation of uncertainty in the observed and predicted values. This uncertainty was carried out using Monte Carlo simulation analysis and simple models to forecast. Uncertainty analysis is important as the estimation of sediments vary greatly from one approach to another. There are three main objectives of this study:

- To examine the relationship between flow discharge and suspended sediment rate using onsite data collection at UTM and Ledang Heights, Nusajaya

- To forecast accumulated sediment loads and depth from MUSLE over 10-100 years

- To analyze the uncertainties of sediment loads and depth using Monte Carlo Simulation combining normal distribution

Literature review: Sediment eroded from disturbed activities from urbanized area (Senior et al., 2003) and soil materials are transported by surface runoff and deposited downstream and detention ponds. Heal et al. (2006) stated that sediment accumulates in detention ponds and impounded water bodies over time affected their chemical, physical and biological processes. Detention pond functions are affected by various factors such as sediment production, sediment transportation rate, sediment type, mode of sediment deposition, detention operation and design and stream flow variability. Predicting the sediment coming into a detention, its deposition and its accumulation throughout the years have been an important problems in hydraulic engineering (Salas and Shin, 1999).
Continued accumulation and deposition of sediments may lead to the deterioration of water quality and the migration of pollutants through sediments. Routine removal of accumulated sediments may be necessary to minimize the risk of contamination and maximize the operational efficiency of the pond. The frequency of removal and the handling of accumulated sediments require a full understanding of both the quantity and quality of these sediments characteristics. This study estimated the probability occurrence of sediment accumulation in terms of loads and depths that may eventually effect the operation of detention pond.

The deposition of sediments can reduce pond storage capacity and fills shallow areas. In estimating detention sedimentation and sediment accumulation, either by empirical or analytical approaches, a number of uncertainties will arise (Salas and Shin, 1999). Empirical models, based on surveys and field observations, have been developed and applied to estimate annual reservoir sedimentation load, accumulated reservoir sedimentation load and accumulated reservoir sedimentation volume after a given number of years of reservoir operation (Strand and Pemberton 1982; Morris and Fan 1998). Also mathematical models for predicting reservoir sedimentation based on equations of motion and continuity for water and sediment Chen et al. (1978); Soares et al. (1982), Morris and Fan (1998); France, 2002. There are several uncertainty analysis have been developed and applied in water resources engineering for an example uncertainty models such as First-Order Analysis (FOA) and Monte Carlo Simulation (MCS) (Yen et al., 1986). All the analysis was carried out intentionally to get the better management of water resources and the best practical operational design of detention pond in our country.

\section{MATERIALS AND METHODS}

This study was conducted at two particular areas; Ledang Heights, Nusajaya Johor and Universiti Teknologi Malaysia, UTM Skudai, Johor Bahru. The catchment of Ledang Heights, Nusajaya consist of 361.01 acres $\left(1.46 \mathrm{~km}^{2}\right)$ of residential area. The detention pond was design for 100 years major storm design and having about 10 acres mainly for recreational activities. The catchment of UTM area is about $11 \mathrm{~km}^{2}(2718.16$ acre) and it is separated into 10 sub basins. This study only focuses on detention pond at sub basin $1\left(31.09\right.$ acre or $\left.125,800 \mathrm{~m}^{2}\right)$. Name of that detention pond is KolamTahanan 1 and the area for this pond is 3.36 acre or $13,607 \mathrm{~m}^{2}$. 
Data collection: There are three stations selected at inlet and one station at the outlet of the pond for the data collection. The field study was carried out three times. The flow discharge was obtained using Velocity-Areamethod. The velocity was measured using Swoffer 2100 at each station. There were two water samples collected at each station near the inlet and four samples at each station near the outlet of the detention pond at Ledang Heights for water quality parameter analysis. Two water samples were collected at the inlet and four samples were taken at the outlet of the detention pond at UTM.

Laboratory test: The samples obtained from site were brought to the Environmental Laboratory for analysis. In the laboratory, the Total Suspended Solid (TSS) experiment was carried out to measure the sediment suspended concentrations. The suspended sediment rate was obtained from suspended solid concentration as shown below Eq. 1 and 2:

Suspendeds sediment Rate, Qs(tons / day) =

$\mathrm{P}_{\mathrm{m}} \mathrm{xSxqx} 86400 \times 10^{-6}$

Where:

$$
\mathrm{p}_{\mathrm{m}}=\frac{\mathrm{ps}}{\left(\mathrm{ds}-\left(\mathrm{s} \times 10^{-6}\right)(\mathrm{ds}-\mathrm{dw})\right)}\left(\text { tons } / \mathrm{m}^{3}\right)
$$

$\mathrm{S}=$ TSS concentration $(\mathrm{mg} / \mathrm{L})$

$\mathrm{Q} \quad=$ Flow discharge $\left(\mathrm{m}^{3} / \mathrm{sec}\right)$

Ps @ ds = Bulk density of sediment $=2.65$ tons $/ \mathrm{m}^{3}$

$\mathrm{dw}=$ Bulk density of water $=1$ tons $/ \mathrm{m}^{3}$

$86400=$ is conversion factor from seconds to day unit

Then, the accumulated sediment in detention pond can be obtained from suspended sediment rate by applying the conversion factor as shown in Eq. 3 JPS, 1977:

Sediment depth, $d(m m) Q_{s} \cdot \frac{1}{p_{s}} \cdot \frac{1}{A}$

Where:

Qs = Suspended sediment rate (tons/day)

Ps $=$ Bulk density of sediment $\left(2.65\right.$ tons $\left./ \mathrm{m}^{3}\right)$

$A=$ Surface area of detention pond $\left(13,607 \mathrm{~m}^{2}\right)$

Estimating sediment yield using musle equation: As reported by Brooks (2003), USARS (1974) modified the Universal Soil Loss Equation (USLE) and developed the Modified Universal Soil Loss Equation
(MUSLE) by replacing the rainfall energy factor in the USLE with a runoff energy factor in the MUSLE. The modification is based on the assumption that the total discharge rate resulting from a storm on the watershed depend on the duration, amount and intensity of the storm. The MUSLE Eq. 4 is :

$$
\mathrm{y}=11.8\left(\mathrm{Q} \cdot \mathrm{q}_{\mathrm{p}}\right)^{0.56} \cdot \text { K.C.P.LS }
$$

Where:

$$
\begin{aligned}
\mathrm{y}= & \text { Sediment yield (tons) } \\
\mathrm{Q}= & \text { Runoff volume }\left(\mathrm{m}^{3}\right) \\
\mathrm{Qp}= & \text { Peak runoff rate }\left(\mathrm{m}^{3} / \mathrm{sec}\right) \\
\mathrm{K}= & \text { Soil Erodibility Factor } \\
\mathrm{C}= & \text { Dimensionless Crop Management Factor } \\
\mathrm{P}= & \text { Erosion Control Practice Factor } \\
\mathrm{LS}= & \text { Topographic Factor, a combined } \\
& \text { dimensionless factor for Slope Length and } \\
& \text { Slope Gradient } \\
11.8= & \text { Is conversion factor for metrics system }
\end{aligned}
$$

Regression analysis: The prediction function based on regression analysis can be used to predict new values on a least-squares linear regression of range of known data. Least-squares fit of straight line to graph of response variable versus one predictor variable can be wrote as Eq. 5:

$$
\mathrm{Y}=\mathrm{mx}+\mathrm{c}
$$

Where:

$$
\begin{aligned}
& \mathrm{y}=\text { Dependent variable } \\
& \mathrm{x}=\text { Independent variable } \\
& \mathrm{m}=\text { Slope of the graph } \\
& \mathrm{c}=\text { The } \mathrm{y} \text {-interception }
\end{aligned}
$$

The regression analysis was applied for MUSLE output where the variables were sediment load and sediment depth. Thisregression analysis predicted the sediment load and depth for the next 100 years (20102110). The prediction was carried out using rainfall data from 2000 until 2010.

The monte carlo simulation: The Monte Carlo method was applied to solve a wide range of physical and mathematical problems. The Monte Carlo simulation was applied using RiskAMP Monte Carlo Add-in and it installed into Microsoft Excel to run the simulation process. Normal distribution was applied because it is easy method and need the simple parameters for the mean, $\mu$ and standard 
Am. J. Environ. Sci., 8 (1): 25-34, 2012

deviation, $\sigma$ for the distribution process. Besides that, the histogram and probability distribution functions can be quickly and automatically generated. The functions of this normal distribution use for this simulation are as follows:

NornalDistribution inMCS, $\mathrm{f}_{\mathrm{x}}=$ normal value $(\mu, \sigma)$

The histogram of sample and the probability density function will be produced from the simulation.

\section{RESULTS AND DISCUSSION}

\section{Flow discharge measurement and suspended} sediment rate:

Detention pond at kolam tahanan 1, UTM, Johor: The flow discharge was observed based on the Velocity-Area mid and mean section method using Swoffer 2100 at each station located at the inlet and outlet of the pond. The average flow discharge was calculated at every station located at inlet and outlet for three consecutive days for inlet and outlet of the detention pond as shown in Table 1.

The Total Suspended Solid (TSS) obtained from the labarotary was used to estimate the sediment suspended concentrations. There were 18 samples taken from the inlet and 12 samples taken from the outlet of the detention pond for TSS estimation. The results obtained from the TSS was measured in $\mathrm{mg} / \mathrm{L}$ and later converted into tons/day.

The relationship between 18 values of flow discharge, Q and suspended sediment rate, Qs at the inlet of detention pond can be showed by suspended sediment rating curve on Fig. 1.

Detention pond at ledang heights, Johor: The analysis from 30 samples at the inlet and 18 samples at the outlet were carried out for suspended sediment concentration estimation. The suspended sediment data from TSS experiment $(\mathrm{mg} / \mathrm{L})$ was converted into the rate unit, which is tons/day. Then, all the flow discharge data and TSS data was averaged. Table 2 showed the average value of flow discharge and suspended sediment rate measured on 20/April/2010, 27/April/2010 and 13/May/2010.

The relationship between the flow discharge and incoming sediment load or sediment rating curve was shown on Fig. 2. This sediment rating curve was applied for sediment loads forecasting.
Table 1: Average value of flow discharge, Q (UTM detention pond) Flow Discharge, $\mathrm{Q}\left(\mathrm{m}^{3} / \mathrm{sec}\right)$

\begin{tabular}{lll} 
Date & Inlet & Outlet \\
\hline $08 / 02 / 2010$ & 0.0047 & 0.0025 \\
$22 / 02 / 2010$ & 0.0046 & 0.0005 \\
$08 / 03 / 2010$ & 0.0131 & 0.0028 \\
\hline
\end{tabular}

Table 2: Average value of flow discharge and suspended sediment rate (Ledang Heights, Johor)

\begin{tabular}{lllll}
\hline & \multicolumn{2}{l}{$\begin{array}{l}\text { Flow discharge, } \\
\mathrm{Q}\left(\mathrm{m}^{3} / \mathrm{sec}\right)\end{array}$} & $\begin{array}{l}\text { Suspended sediment } \\
\text { rate, Qs (tons/day) }\end{array}$ \\
\hline Date & Inlet & Outlet & Inlet & Outlet \\
\hline 20/April/2010 & 0.007 & 0.018 & 0.002 & 0.008 \\
27/Apri1/2010 & 0.002 & 0.004 & 0.003 & 0.022 \\
13/May/2010 & 0.003 & 0.012 & 0.004 & 0.007 \\
\hline
\end{tabular}

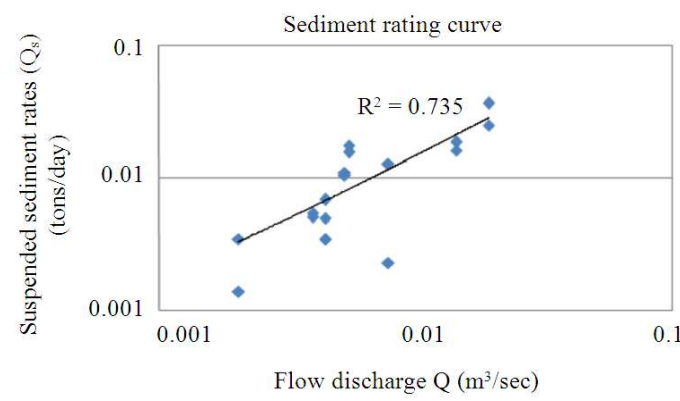

Fig. 1: Sediment rating curve for the observed data (UTM Detention Pond)

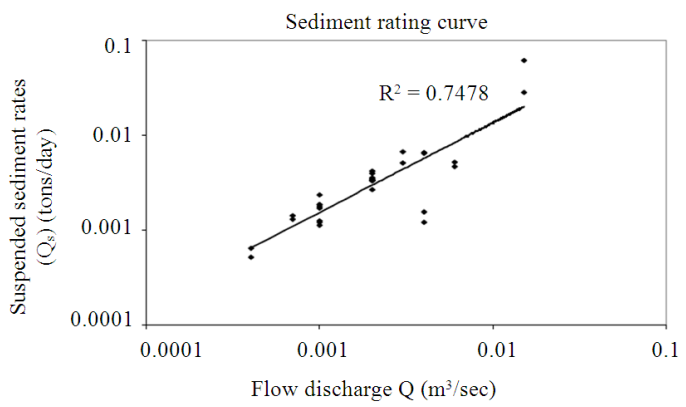

Fig. 2: The sediment rating curve for observed data (Ledang Heights, Johor)

\section{Prediction analysis:}

Detention pond at KolamTahanan 1, UTM, Johor: Sediment yield in this study was calculated using MUSLE method, Eq. 4. The daily rainfall data for ten years duration (2000-2010) was obtained from the JPS, Johor Bahru to calculate the monthly and yearly rainfall depth, P. Based on type of soil in UTM, the K value used for this study was 0.27 (sandy clay loam). 


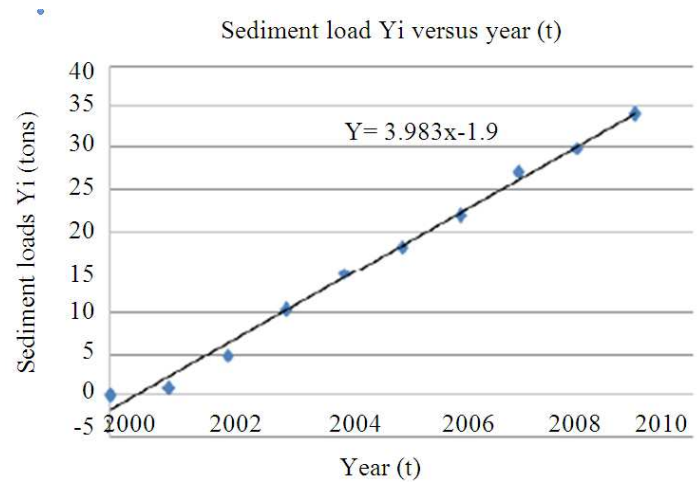

(a)

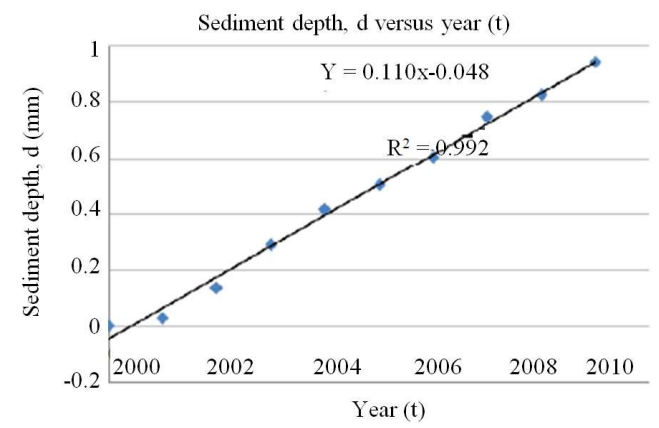

(b)

Fig. 3: Linear regression equation for sediment loads and sediment depth

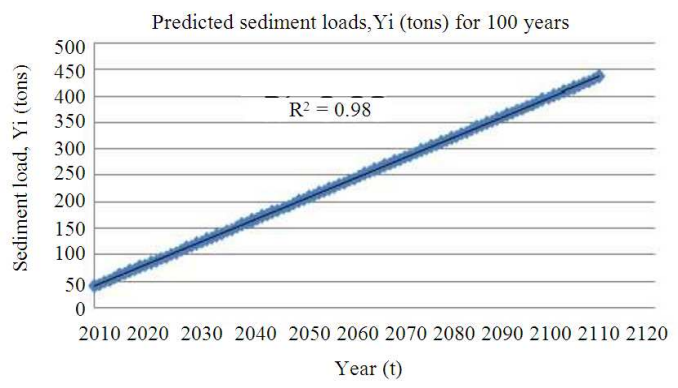

Fig. 4: Sediment loads, Yi (tons) projection for100 years

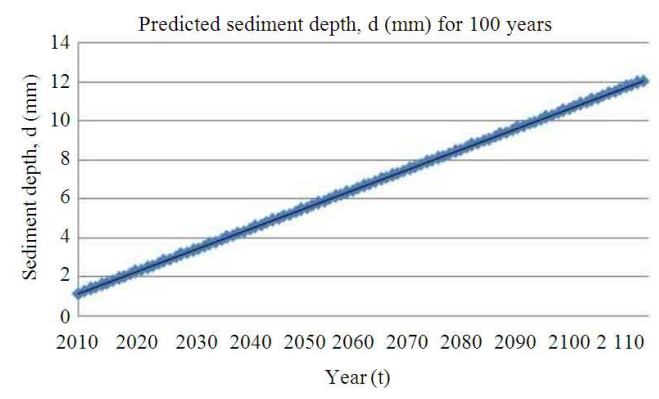

Fig. 5: Sediment depths, d (mm) projection for100 years

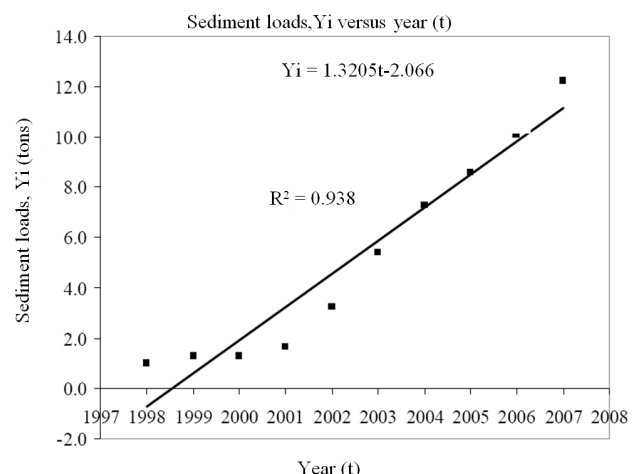

(a)

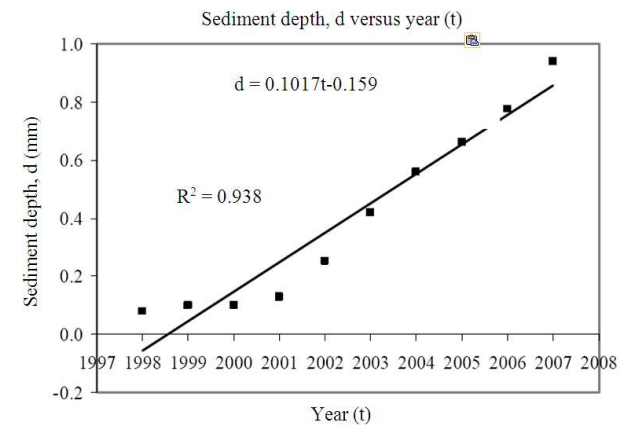

(b)

Fig. 6: Linear regression equations for sediment loads and sediment depth

After that, the value of CP and LS used were 0.0096 and 4.30 respectively. Then sediment depth, $\mathrm{d}$ was obtained using Eq. 3.The sediment loads, Yi was obtained from the value of $y$ (MUSLE) divided by 1 year. The sediment loads, Yi and sediment depth, d data was computed using MUSLE and Eq. 5 as shown in Fig. 3a and b. Linear equations as shown were produced with their significant $r^{2}$ values of 0.992 and 0.994 respectively.

Figure 4 and 5 showed, the sediment loads and sediment depths increased linearly over the next 10 to 100 years (2010 until 2110). The predicted sediment loads and sediment depths were made under the assumption there would be no major watershed and land use changes. For the next 10 years, the sediment loads would be 41.913 tons, the nit increased 436.230 tons over the next 100 years. This situation was similar for the prediction of sediment depths that was from $1.162 \mathrm{~mm}$ on 10 years to $12.052 \mathrm{~mm}$ on 100 years. The depth of detention pond in this study was 3 $\mathrm{m}$, so $12.052 \mathrm{~mm}$ was a small value of sediment depths compared to the depth of detention pond. Therefore it may not affect the operation of detention pond for 100 years duration. Unless there are major problems such as gully, bank erosion. 
Detention pond at ledang heights, Johor: Sediment load was estimated using MUSLE method Eq. 4. The daily rainfall data for ten years duration (1998-2007) was obtained from the JPS, Johor Bahru to calculate the monthly and yearly rainfall depth, $\mathrm{P}$. The fraction value of particle and size distribution at the site, the soil erodibility, $\mathrm{K}$ was assumed to be 0.25 . The LS factor and $\mathrm{CP}$ factor used in this equation were 0.66 and 0.003 respectively. Then the sediment depth was calculated using Eq. 4. Figure 6a and b below showed the linearregression equation for sediment loads and sediment depth respectively.

The equation of sediment loads and sediment depth were obtained from the regression with coefficient, $R^{2} 0.938$. The significant value of $R^{2}$ indicates a significant relationship between sediment loads and depth with time (year). The significant $\mathrm{R}^{2}$ tell that the sediment loads and sediment depth increased through time. Then, this linear equation was used to forecast the sediment loads and sediment depth for the next 100 years from 2010 until 2110.

The averaged Trap Efficiency (TE), f value from Eq. 5 at $41.7 \%$ was used to predict the accumulated sediment load in detention pond in one year. The sediment load accumulation in detention pond were assumed uniform and constant for every year, therefore a linear multiplication of number of years was carried out in Eq. 7. The sediment load was forecasted for the next 100 years duration from 2010 until 2110. The depth of the sediment accumulated in detention pond was measured by multiplying the accumulated sediment load with the area of the detention pond.

Figure $7 \mathrm{a}$ and $\mathrm{b}$ showed the graphs of predicted sediment loads and sediment depth for 100 years duration from 2010 until 2110 respectively. The average value for sediment loads calculated from MUSLE and trap efficiency method was 77.284 tons and 60.991 respectively. While the average value for sediment depth from MUSLE and trap efficiency method was $5.952 \mathrm{~mm}$ and $4.697 \mathrm{~mm}$ respectively. The percentage of differences between this average values for both approaches was $21.1 \%$. In addition, the projection analysis for both approaches showed that the percentage differences become less when the number of year forecasted increased.

Monte carlo simulation analysis: Monte Carlo simulation was used to obtain the uncertainty and range of value of sediment loads and sediment depth based on the collected data from the detention pond.

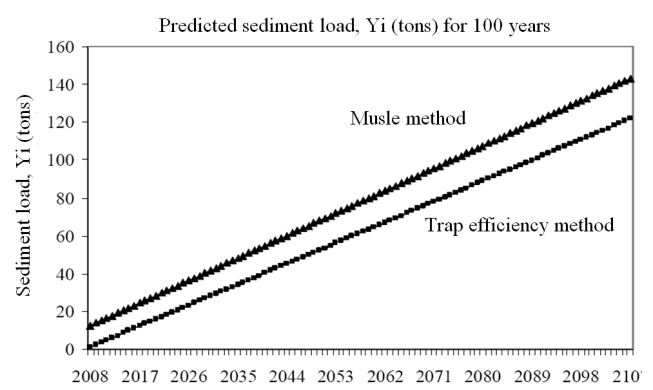

Year (t)

(a)

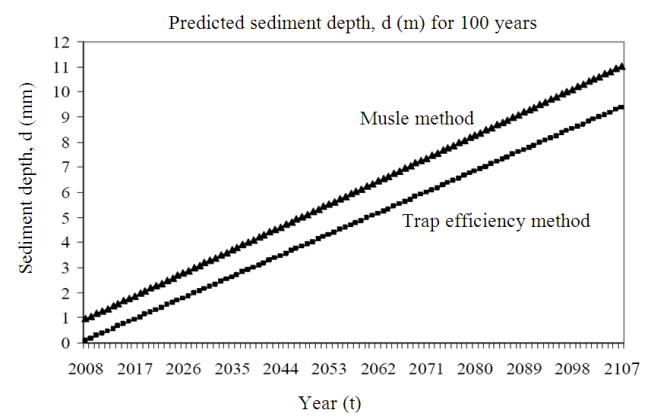

Fig. 7: Predicted sediment loads and sediment depth for 100 years duration

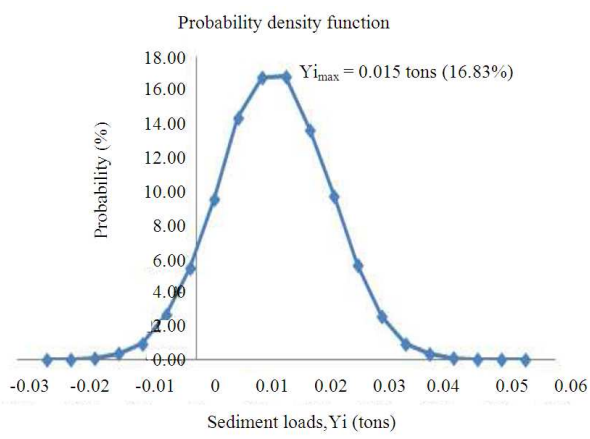

(a)

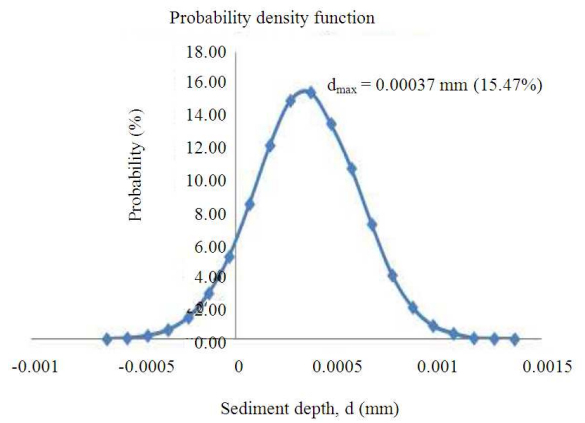

(b)

Fig. 8: Probability density function of observed sediment loads and sediment depth for 20,000 trials 
Am. J. Environ. Sci., 8 (1): 25-34, 2012

Monte Carlo simulation was applied using RiskAMP The uncertainties of sediments estimation vary greatly due to the hydrological variability and rainfall random nature. Danazumi et al. (2010) elaborate about the hydrological variablity and the distribution of rainfall Intensity which provides the basic concepts for this simulation. Monte Carlo Add-in and is installed into Microsoft Excel and the hypothesis data collected was assumed to be normally distributed. The simulation was run using the average or mean value, $\mu$ and standard deviation value, $\sigma$ of sediment loads, Yi and sediment depth, $\mathrm{d}$ for each case.

Detention pond at KolamTahanan 1, UTM, Johor: Monte carlo simulation for observed sediment

loads and sediment depth: The various numbers of trials for observed sediment loads, Yi and sediment depth using Monte Carlo Simulation, produced several conclusions, firstly, when the number of trials increased, the mean and standard deviation from simulation become closer with actual mean or average and actual standard deviation. Besides, if the number of trials increased, the standard error from simulation become smaller. Lastly, the value of skewness and kurtosis from the simulation became closer to the best value which is 0 and 3 respectively when the number of trials became larger.

Figure $8 \mathrm{a}$ and $\mathrm{b}$ showed the Probability Density Function of observed sediment loads and sediment depth for 20,000 trials to know the maximum value of sediment loads and sediment depth from that simulation.

From Figure $8 \mathrm{a}$ and $\mathrm{b}$ above, showed that the maximum value of sediment loads and sediment depth were 0.015 tons $(16.83 \%)$ and $0.00037 \mathrm{~mm}(15.47 \%)$ respectively. The most likely range for sediment loads obtained was from 0.007-0.019 tons (14.36-13.64\%) and then for sediment depth obtained was from 0.00017$0.00047 \mathrm{~mm}$ (12.14-13.49\%). Beside that, both curves give the best bell shape of normal curve.

Monte carlo simulation for predicted sediment loads and sediment depth: The various numbers of trials for predicted sediment loads, Yi and sediment depth using Monte Carlo Simulation, produced several conclusions which is similar to the simulation for observed data. Figure $9 \mathrm{a}$ and $\mathrm{b}$ showed the Probability Density Function of predicted sediment loads and sediment depth for 20,000 trials.

Monte Carlo simulation generally showed the maximum probability of occurrence value for the predicted sediment loads and sediment depth using MUSLE method were 264 tons (15.70\%) and $7.00 \mathrm{~mm}$ $(21.16 \%)$ respectively. The most likely range for predicted sediment loads and sediment depth obtained varied from 160-316 tons (11.50-14.49\%) and 5-11 $\mathrm{mm}(16.96-14.33 \%)$ respectively.

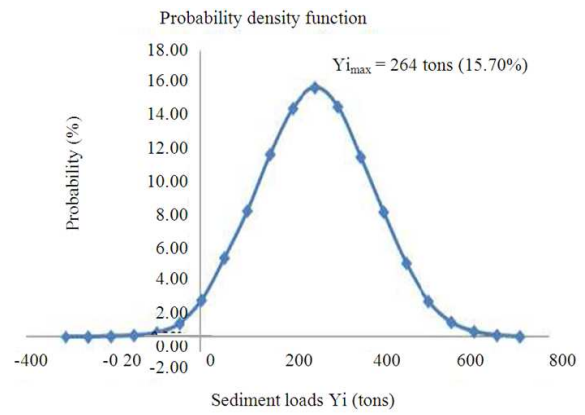

(a)

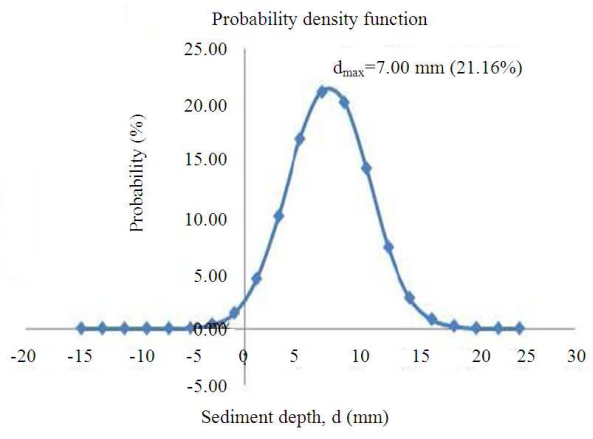

(b)

Fig. 9: Probability density function of predicted sediment loads and sediment depth for 20, 000 trials

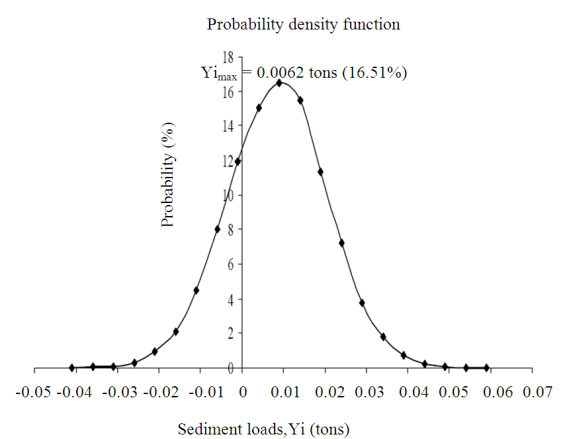

(a)

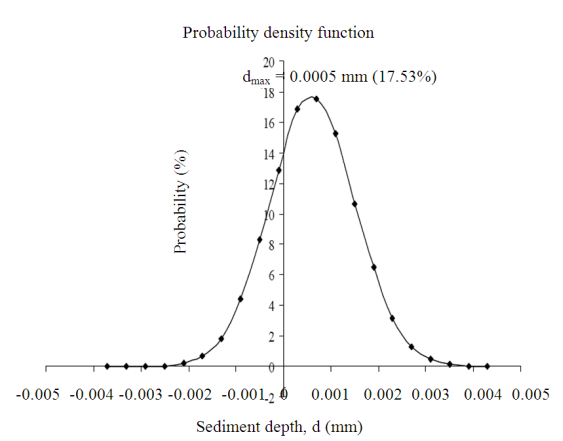

(b)

Fig. 10: Probability density function of observed data for 20,000 trials (Monte Carlo Simulation) 
Am. J. Environ. Sci., 8 (1): 25-34, 2012

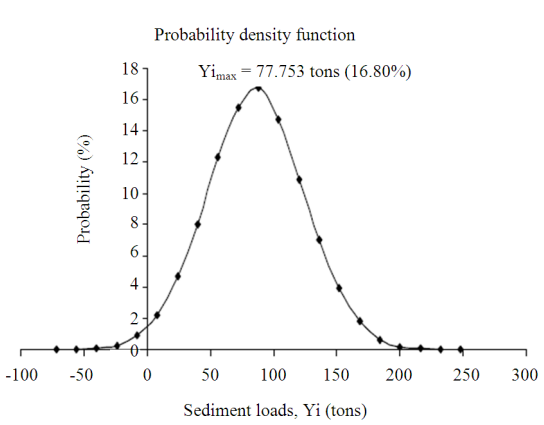

(a)

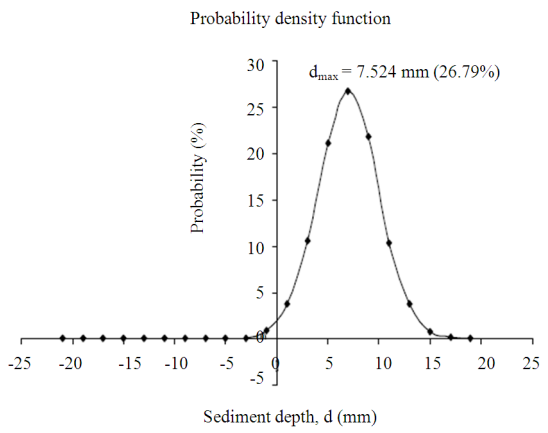

(b)

Fig. 11: Probability density function of predicted data for 20,000 trials (Monte Carlo Simulation)

Detention pond at ledang heights, Johor: Monte carlo simulation for observed sediment loads and sediment depth: These most likely values were estimated from the fourth higher values of the probability density curve. These most likely values were represented the range for probability of sediment loads and sediment depth to occur within the study was done. These probability values can be shown in the probability density curve (Fig. 10).

Figure $10 \mathrm{a}$ and $\mathrm{b}$ showed the maximum value of sediment loads and sediment depth at 0.062 tons $(16.5 \%)$ and $0.0005 \mathrm{~mm}(17.5 \%)$ respectively. The most likely range for sediment loads obtained was from 0.0031-0.0077 tons (11.9-15.5\%) and then for sediment depth obtained was from 0.0003-0.0006 mm (12.8-15.2\%). Besides that, both curves give the best bell shape of normal curve.

\section{Monte carlo simulation for predicted sediment loads and sediment depth: The predicted sediment loads and sediment depth were calculated using MUSLE and trap efficiency method. The predicted data and uncertainty was analyzed by Monte Carlo simulation. This was indicated by the percentage probability (Fig. 11 and 12).}

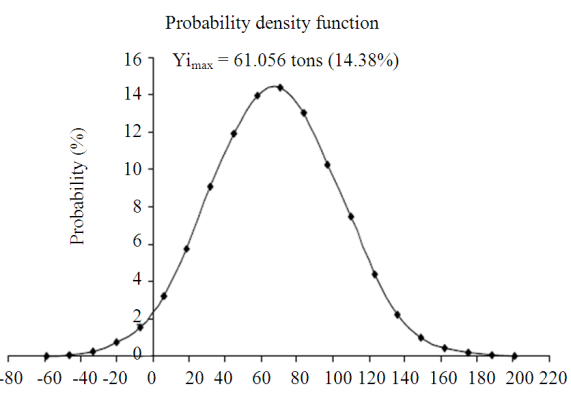

Sediment loads, Yi (tons)

(a)

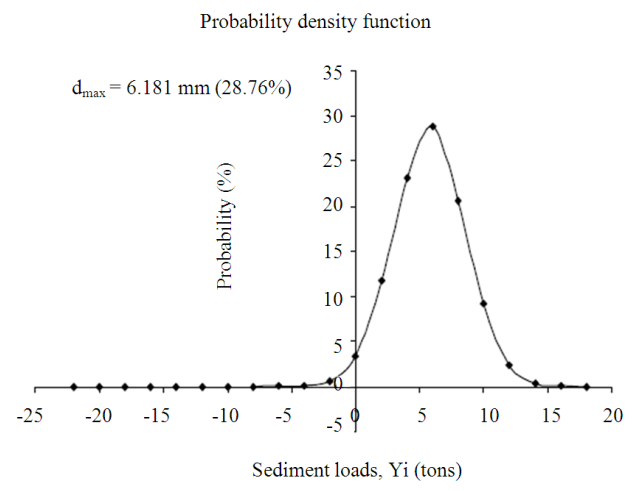

(b)

Fig. 12: Probability density function of predicted data for 20,000 trials (Trap Efficiency Method)

Table 3: Comparison for sediment loads, Yi

\begin{tabular}{llcll}
\hline & Observed data & \multicolumn{2}{l}{ Predicted data } \\
& Maximum & $\begin{array}{c}\text { Maximum } \\
(\%)\end{array}$ & $\begin{array}{l}\text { Maximum } \\
\text { value (tons) }\end{array}$ & $\begin{array}{c}\text { Maximum } \\
(\%)\end{array}$ \\
Note & Value (tons) & $(6.5$ & 77.70 & 16.8 \\
Ledang heights & 0.0062 & 16.8 & 264.00 & 15.7 \\
UTM & 0.0150 & 16.8 &
\end{tabular}

Table 4: Comparison for sediment depths, d

\begin{tabular}{|c|c|c|c|c|}
\hline \multirow[b]{2}{*}{ Note } & \multicolumn{2}{|c|}{ Observed data } & \multicolumn{2}{|c|}{ Predicted data } \\
\hline & $\begin{array}{l}\text { Maximum } \\
\text { value }(\mathrm{mm})\end{array}$ & $\begin{array}{l}\text { Maximum } \\
(\%)\end{array}$ & $\begin{array}{l}\text { Maximum } \\
\text { value }(\mathrm{mm})\end{array}$ & $\begin{array}{l}\text { Maximum } \\
(\%)\end{array}$ \\
\hline Ledang heights & 0.0005 & 17.5 & 7.5 & 26.8 \\
\hline UTM & 0.0003 & 15.4 & 7.0 & 21.1 \\
\hline
\end{tabular}

Showed the maximum probability of occurrence value for predicted sediment loads and depth by MUSLE method were 77.7 tons (16.8\%) and $7.52 \mathrm{~mm}$ (26.8\%) respectively (Fig. 11 and 12). While the maximum probability of occurrence value for predicted sediment loads and depth by trap efficiency method were 61.1 tons $(14.4 \%)$ and $6.181 \mathrm{~mm}(28.8 \%)$ respectively. The most likely range for predicted sediment loads obtained varies from 68.1-82.5 tons (12.3-14.7\%) and 52.1-66.7 tons (11.9-13.1\%) for MUSLE and trap efficiency methods respectively. The 
most likely range for predicted sediment depth was 6.8-7.9 $\mathrm{mm}(10.5-21.8 \%)$ and 5.4-6.6 $\mathrm{mm}$ (11.7$20.5 \%$ ) for each methods. Both MUSLE and trap efficiency methods produced reasonably similar estimations however varies from the two case studies.

Comparison for the two areas of study: The studies at Ledang Height, Nusajaya, Johor were compared to KolamTahanan 1, UTM, Johor. Both studies were compared as shown in Table 3 and 4.

The results showed that the value for sediment loads, Yi obtained from Ledang Heights study were lower than the value obtained from UTM. The values of sediment depth, d from Ledang Heightswere deeper than UTM. The results from both location were different because they have different of catchment area, different of detention pond area and time for both study also different.

\section{CONCLUSION}

The conclusions that can be drawn from this study are as follows:

- The on-site data collection relationship between suspended sediment rate, Qs and flow discharge, $\mathrm{Q}$ was obtained. The deposition of sediments into the detention pond were observed

- The accumulation of sediment loads and sediment depth for 10 years were estimated using MUSLE method and the linear increment of sediment loads and sediment depth with time was obtained

- This linear equation predicted the scenario for the next 100 years. The longer of the life time of the detention pond, the heavier sediment loads and deeper the sediment depth would be accumulated

- The uncertainties of sediments estimation from MCS vary greatly due to the hydrological variability and rainfall random nature.

- Monte Carlo simulation also showed the maximum probability of occurrence value for predicted sediment loads and sediment depth in the detention pond

- This study provides the methodology to determine and predict the sediment accumulation in detention pond for next 100 years

- Determining and forecasting the sediment accumulation in detention pond are very important to ensure the effectiveness of the detention pond. Last but not list, the maintenance of detention pond also important to make sure that the detention pond can function properly throughout their lifespan

- Better result for observed sediment loads and sediment depth can be obtained if more sample at site were collected over longer time period. This is because it can give more accurate values in the calculation of prediction for sediment loads and sediment depth in detention pond

- Geographic Information System (GIS) usage are encouraged because it use widely and slope length and slope gradient factor, LS and crop management factor, $\mathrm{CP}$ can be obtained more accurately. This system also can be used to determine the soil loss, then comparison could be made between result from GIS and result using common method

\section{ACKNOWLEDGEMENT}

All the authors are thankful for everyone involved directly and indirectly for making this study a successful one. Especially for the technicians of UTMFKA Hydraulics and Hydrology Laboratory who had help with the onsite data collection during this study endeavour, you all are just great. The authors are also very thankful for the Ministry of Science, Technology and Innovation (MOSTI), Malaysia for the provision of research grant VOT 79394.

\section{REFERENCES}

Brooks, K.N., N.B., 2003. Hydrology and the Management of Watersheds. 3rd Edn., WileyBlackwell, Ames, ISBN-10: 0813829852 pp: 574.

Chen, Y.H., E.V. Richardson and J.L. Lopez, 1978. Mathematical modeling of sediment deposition in reservoirs. J. Hydraulics Div., 104: 1605-1616.

Danazumi, S., S. Shamsudin and A. Aris, 2010. Modeling the distribution of rainfall intensity using hourly data. Am. J. Environ. Sci., 6: 238243. DOI:10.3844/ajessp.2010.238.243

France, R.L., 2002. Handbook of Water Sensitive Planning and Design. 1st Edn., Lewis Publishers, Boca Raton, ISBN-10: 1566705622, pp: 699.

Heal, K.V., D.A. Hepburn and R.J. Lunn, 2006. Water Science and technology. Sediment Manage. Sustainable Urban Drainage Syst. Ponds, 53: 219227.

Morris, G.L. and J. Fan, 1998. Reservoir Sedimentation Handbook: Design and Management of Dams, Reservoirs and Watersheds for Sustainable Use. Ist Edn., McGraw-Hill Professional, New York, ISBN-10: 007043302X pp: 848.

Salas, J.D. and H.S. Shin, 1999. Uncertainty analysis of reservoir sedimentation. J. Hydraulic Eng., 125: 339-350. DOI: 10.1061/(ASCE)0733-9429 
Senior, A., M. Green and J. Oldman, 2003. Hydrobiologia. Using Deterministic Models to Assess Risk in Sediment-Impacted Estuaries. Hydrobiologia, 494: 11-16. DOI: 10.1023/A:1025464820912

Soares, E.F., T.E. Unny and W.C. Lennox, 1982. Conjunctive use of deterministic and stochastic models for predicting sediment storage in large reservoirs: 2. Deterministic model for the sediment deposition process. J. Hydrol., 59: 83105. DOI: $10.1016 / 0022-1694(82) 90004-\mathrm{X}$

Strand, R.I. and E.L. Pemberton, 1982. Technical guideline for Bureau of Reclamation. 1st Edn., Sedimentation and River Hydraulics Section, USA., pp: 48.
USARS, 1974. Present and Prospective Technology for Predicting Sediment Yields and Sources. Ist Edn., Agricultural Research Service, USA., pp: 200.

Yen, B.C., S.T. Cheng and C.S. Melching, 1986. First Order Reliability Analysis, Stochastic and Risk Analysis in Hydraulic Engineering. In: Water Resources Publications, Yen, B.C. (Ed.). Littleton, Colo, pp: 1-36. 